\title{
Urban robotics and responsible urban innovation
}

\author{
Michael Nagenborg ${ }^{1}$ (i)
}

Published online: 30 January 2018

(c) The Author(s) 2018. This article is an open access publication

\begin{abstract}
Robots are leaving factories and entering urban spaces. In this paper, I will explore how we can integrate robots of various types into the urban landscape. I will distinguish between two perspectives: (1) the responsible design and use of urban robots and (2) robots as part of responsible urban innovations. The first viewpoint considers issues arising from the use of a robot in an urban environment. To develop a substantive understanding of Responsible Urban Robotics, we need to focus on normative implications of city life as the context in which in robots are being used. I will refer to the desirable qualities of city life as "cityness" and will argue that we should design for cityness. The second approach asks how robots might be used to address challenges specific to cities. From the perspective of RRI, this may require participatory approaches in which the needs of the stakeholders are addressed. But we may also find inspiration in the work undertaken in architecture on expanding the concept and field to ensure that architects not only provide services to the lucky few but also create useful and beautiful spaces for the many. A dialogue with architects, urban designers, and urban planners may also be needed to successfully address the spatial issues raised by the presence of robots in the city.
\end{abstract}

Keywords Urban technologies · Responsible Research and Innovation · Cityness · Urban justice $\cdot$ Urban planning $\cdot$ Selfdriving cars

\section{Introduction}

Robots are leaving factories and entering urban spaces. The city of Amsterdam appears particularly attractive for robots. The company MX3D combined an industrial multi-axis robot with 3D printing capabilities to build a bridge over the Oudezijds Achterburgwal canal (Kedmey 2015). According to a press release of MIT's Senseable City Lab, the "RoBoat" will be tested in Amsterdam in 2017: "Each water-based unit (a 'RoBoat') can be used for transporting goods and people and for creating temporary floating infrastructures, such as self-assembling bridges and concert stages. RoBoats can also monitor the city's waters using new environmental sensors that provide vital insights on urban and human health." The use of robots to build cities seems to be rather new, evidenced by the foundation of the Association for Robots in Architecture in 2010 (Association for Robots in Architecture, n.d.) and the recent initiation of the "Self Repairing Cities"

Michael Nagenborg

m.h.nagenborg@utwente.nl

1 Philosophy Department, University of Twente, Post Box 217, 7500 AE Enschede, The Netherlands project that aims "to make Leeds the first city in the World that is fully maintained autonomously by 2035" with the help of robots. (Self Repairing Cities 2018). Of course, some of the examples given need to be understood for what they are: experiments, early adaptations, and-at times-marketing tools. We are in an early phase, and it remains difficult to predict the extent to which robots will actually be integrated into human societies and thus into our cities.

In this paper, I will explore the possible meaning of integrating various types of robots into the urban landscape. Although differentiating between various kinds of robots and distinguishing between the particular usage of robots in different contexts is important, in this paper I will highlight one common feature of these robots: They are spatial entities and will need to find a place in the city. Thus, any type of robot will at least bring a new spatial entity into urban spaces and may potentially require the rearrangement and redesign of existing spatial entities. ${ }^{1}$

Humanoid robots with a similar size and weight to human beings may have the advantage of being able to use

\footnotetext{
${ }^{1}$ Given the specific focus of this paper, I will remain relative silent on the potential economic impact of urban robotics (e.g., displacement of bus and taxi drivers through automation).
} 
structures designed for humans. However, any deviation from the culturally and materially embedded body norms may result in a disabling environment for such machines in much the same way that similar differences would be disabling for humans. ${ }^{2}$ Thus, a question arises whether we should build cities for robots or robots for cities. The answer to this question is likely to be found in a mixed approach, where the built environment will be adopted to enable new robotic applications while safeguarding the quality of city life. Furthermore, it seems unlikely to imagine a sudden change in the urban space such as a switch from humandriven vehicles to fully automated vehicles. A more likely scenario is the introduction of some forms of robotic systems, which may shape some parts of the city and create a new space for other developments. Hence, thinking about urban robotics requires us to look at a longer and complex co-shaping process than the examples in this paper may suggest at first glance.

Robots may also allow for new forms of production and design of the urban landscape, and robotic system might become part of the build environment. Again, these developments will impact urban spaces and shape the lives of city dwellers. Hence, we need to ask if and how we want robots to shape our cities.

In this paper, I will distinguish between two perspectives: (1) the responsible design and use of urban robots and (2) robots as part of responsible urban innovations. The first viewpoint considers issues arising from the use of robots in urban environments. I will develop this perspective by taking the general discussion on the idea of "Responsible Research and Innovation" (RRI) as a starting point and by outlining the general requirements for responsible robotics. In a second step, I will ask about the specific requirements for urban robots. The second approach asks how robots might be used to address challenges specific to cities. While the two approaches are distinct due to the different entry points, they are not meant to be mutually exclusive. Ideally, any responsible design and use of a robot should be thought of as a responsible urban innovation. In a less than ideal world, however, it seems reasonable to assume that some robots will be integrated into the urban landscape without aiming to address specific urban challenges. Here, taking into account at least the responsible design and use of such robots might be more appropriate.

The purpose of this paper is not to present a final framework or ultimate guidelines for designing and using urban robots. Instead, the goal is to stimulate a discussion of the interplay of robotics and the city and to contribute to the discussion by mapping out potential topics and entry points.

\footnotetext{
${ }^{2}$ Cf. Anderberg (2005) for the interplay between disabilities, tech-
} nologies, and the built environment.

\section{Robots as urban technologies}

In the context of this paper, "urban technologies" refers to technologies that are shaping or are being shaped by city life. The term "urban robots" is used to refer to a specific robot or a specific class of robots as "urban technologies." Robots are considered to be material artefacts that are controlled by a computer and that can sense and manipulate their physical environment. Since the focus in this paper is on the spacetaking and -shaping aspects, so-called soft-bots (software agents) are outside the scope of this paper, because they have a less direct impact on the built environment. The autonomy of robots and robotic systems is likely to become an important aspect in the future, with more detailed inquiries into urban robotics. However, we will not pursue this aspect in the following. Finally, in contrast to "robots," "robotic systems" may not be perceived as an independent entity, because they are integrated into a larger structure. Given the potential impact on the built environment (e.g., in the form of advanced elevators), we include robotic systems in our discussion.

\section{Urban technologies}

Technology is no stranger to the city. It is used to design, build, maintain, govern, and destroy cities and their parts. In addition to the direct ways that technology shapes cities, we must recognize the indirect influence of technology on the built environment. For example, approximately 1900 "urban streets throughout Europe were transformed from multifunctional, relatively empty, and rather disordered places into well-ordered and explicitly zoned spaces in which artefacts, systems, and humans were each given their own place." (Buiter 2008) The pedestrian walk is a by-product of the introduction of trams, busses, cars, and other forms of modern transportation. Once these technologies developed in the multifunctional shared space of the street, the street became fragmented. The idea of creating dedicated "mobile phone lanes" in China and elsewhere (Benedictus 2014) seems to suggest that this zoning of public space continues to be an ongoing process. Indeed, it is difficult to deny that smartphones and other mobile devices must be recognized for shaping the way that we perceive cities and act within them.

At times, the influence of technology on the city is less apparent. One good example of this latent influence is the invention of the modern safety elevator, which was necessary for the construction and use of high-rise buildings (Blumenberg 2009; Graham 2014). In the context of this paper, the term "urban technologies" will be used to refer to technologies such as cars, smartphones, and elevators that shape and are co-shaped by city life. In addition, the concept 
of "urban technologies" is introduced to include technologies such as smartphones and elevators, which lie outside the scope defined by similar concepts such as "urban machinery" (Hård and Misa 2008).

"Urban technologies" is less of an ontological than a hermeneutical concept. That is, "urban technologies" does not refer to a specific type of technology that shares certain properties. The concept is meant to offer a specific perspective on a technology that considers it as urban technology by (a) claiming an interdependence between the technology and the city and (b) focusing on the interplay between the two. For example, by studying elevators as urban technology, we may focus on how they enable new forms of high-rise buildings. From a historical perspective, we may recognize that the development of elevators in the nineteenth century went hand in hand with the development of highrise buildings (Blumenberg 2009). Since high-rise buildings have shaped the modern metropolis (for better or worse), the elevator needs to be understood as an urban technology. Therefore, one may ask what the future development of elevators may imply for buildings and thus cities. Indeed, we currently see new evaluator systems with new and greater capabilities (e.g., speed and height). ThyssenKrupp's Multi system has introduced the idea of horizontal and vertical movement in elevator design, which in turn may reshape the idea of high-rise buildings (Frearson 2014). Seeking seeds of alternative designs of urban space, Easterling (2014) therefore notes: "Since the elevator carries the genetics of the skyscraper, altering its routines has potential collateral effects. For example, contemporary elevator technologies that experiment with horizontal as well as vertical movements are the germ of a very different urban morphology." (Easterling 2014, pp. 74-75) If we are willing to consider advanced elevator systems as robotic applications, such systems should be considered as urban robots, too.

To consider something to be an urban technology does not imply that the technology in question is exclusively designed for and used in cities. The car is a prominent example. On the one hand, it is reasonable to consider the car to be an urban technology because cars have a tremendous effect on city life. If any proof is needed, the discussion of the idea of the car-friendly city should be sufficient in the context of this paper (Lundin 2008). On the other hand, the use of cars is obviously not limited to urban spaces. Following Mumford (1963), one may even argue that the fact that cars are used in the city as well as on the highway is one of the challenges presented by the car, as cities and highways ask for differently designed cars. However, cars were designed for highways rather than cities, especially when highways were introduced. We should not overlook this tension when considering cars as urban technology. Considering something as urban technology is not meant to reduce its meaning to urban usage but to recognize the interplay between that technology and cities regardless of where else the technology is being used.

Finally, to consider something as an urban technology highlights certain features but should not lead to the dismissal of more mundane aspects. To stay with the example of elevators, one still can and should ask how the design of a particular elevator meets and challenges posed by safety standards. In this respect, recent questions concerning the reliability and responsibility of self-driving cars is indeed necessary.

\section{Robots as urban technologies}

As stated earlier, in the context of this paper, "urban robotics" does not refer to a specific class of robots but is used as a term by which to address robots as urban technologies. To say that " $\mathrm{X}$ is an urban robot" should therefore be read as " $\mathrm{X}$ is considered to be an urban technology in the sense that it shapes or is shaped by city life."

"Urban robots" have already been introduced in other research projects and initiatives. For example, the Interactive Urban Robot (IURO) project presented a robot that "navigates autonomously around the city-centre of Munich and commences interaction with pedestrians" (http://www. iuro-project.eu). The European Coordination Hub for Open Robotics Development has created a "Public end-user Driven Technological Innovation (PDTI)" for Urban Robotics, which focuses on sewer inspection (Ajuntament de Barcelona 2014). The Urban Robotics Lab at the Korea Advanced Institute of Science and Technology aimed to combine "Robotics with Civil and Environmental Engineering applications" (Urban Robotics Lab 2018). However, the proposed understanding of both "urban robot" and "urban technology" is broader than in the above examples. In line with what has already been stated regarding "urban technologies", "urban robots" will refer to maintenance robots, social robots interacting in urban spaces and smart transportation systems; these include various forms of self-driving vehicles, wearable robotics, etc. Thus, the term is not limited to the common use of "urban technologies" as a particular field of civil engineering.

Viewing construction robots as urban robots is justified by their direct impact on the built urban environment, but what is the added value of considering other types of robots to be urban technologies? Let us consider the example of the self-driving car. As we have seen in the previous section, it is reasonable to address cars in general as urban technology. Let us further assume that self-driving cars should be considered robots since they are spatial entities that sense the environment, process information, and act in the world based on the information processed. Hence, they meet the traditional "sense-think-act" paradigm of robotics. The current discussion on the responsibility for accidents caused by self-driving 
cars (e.g., Lin 2016) also points to a clear connection to the field of the Ethics of Robotics. Additionally, whereas the current focus on questions of safety and responsibility obviously highlights crucial aspects of the discussion, there is more to be said about the interplay between self-driving cars and the city. For example, self-driving cars may increase the number of vehicle miles travelled (Smith 2012) and therefore contribute to urban sprawl, creating a negative impact on sustainability. At the same time, urban designers have started to consider what streets may look like in a future in which self-driving cars may enable shared spaces (e.g., Skinner and Bidwell 2016). However, debating the type of an urban future selfdriving cars might and should enable is outside the scope of this paper considering that self-driving cars and other forms of smart transportation systems as urban technologies-and thus urban robots-requires the expansion of our discussion on the responsible design and use of such robots in cities by taking into account broader implications for the city.

\section{Responsible robotics}

Before further exploring what the responsible design and usage of urban robotics might entail, let me briefly outline my understanding of responsible robotics as part of the general idea of "Responsible Research and Innovation" (RRI). In Europe, RRI is a central idea that has shaped the research funding schemes provided by the European Commission (such as the "Horizon 2020" program) (van den Hoven et al. 2013). In this context, von Schomberg (2013) has offered the following working definition:

"Responsible Research and Innovation is a transparent, interactive process by which societal actors and innovators become mutually responsive to each other with a view to the (ethical) acceptability, sustainability and societal desirability of the innovation process and its marketable products (in order to allow a proper embedding of scientific and technological advances in our society)."

From the perspective of Ethics (as an academic discipline), three features of this definition need to be emphasized: (1) RRI asks that the ethical acceptability and societal desirability of future products be considered. Whereas the role of Ethics was mostly reduced to the ethical issues of the research undertaken within a specific project, RRI asks for an examination of the broader ethical and societal implications of the outcome of a project. (2) Due to this shift, the idea of value sensitive design ${ }^{3}$ has become a key element in

\footnotetext{
3 This term was introduced by Friedman (1996). The idea has inspired different and related approaches such as values in design (Flanagan et al. 2008) or care-centred value-sensitive design (van Wynsberghe 2013). In the context of this paper, the term "value sensitive design" will be used to cover all these distinctive approaches
}

RRI. Hence, RRI favours a non-instrumental perspective on technologies that are considered to be value-laden (Franssen et al. 2013). (3) The emphasis is on innovations that aim to "expand the set of relevant feasible options regarding solving a set of moral problems." (van den Hoven 2013a; see also:; van den Hoven et al. 2012) In other words, RRI asks researchers and developers of technologies to address morally relevant problems and to strive towards solutions that do not have a negative impact on other moral values. For example, security technologies should incorporate privacyby-design features to do justice to both security and privacy values (van den Hoven et al. 2012).

When expanding the scope to Practical Philosophy by including Political Philosophy, it further needs to be recognized that—following von Schomberg (2013)—RRI is understood as a process that ought to be interactive and transparent and that considers the views of various stakeholders. Thus, RRI includes elements of procedural justice, which is understood as the requirement to involve in a decision-making process all those who are affected by the outcome of that process. As we will see, this allows us to connect the ideas of Responsible Urban Innovation and Urban Justice. At the same time, RRI should not be reduced to a procedural approach as it aims to achieve "(ethical) acceptability, sustainability and societal desirability" (von Schomberg 2013), which requires the commitment to shared societal values. However, as we will see, urban justice cannot be reduced to a procedural account either.

Let us first examine the meaning of RRI in the context of innovations in the field of robotics in general. As we have seen, RRI asks us to develop robots that are (1) helpful in addressing morally relevant challenges and (2) do so in a manner that minimizes any negative impact on other moral values.

Since robots sense the environment in which they act, they are generally likely to have a negative impact on privacy. Since the amount and type of data collected and processed varies for different types of robots, we are asked to distinguish between different robots. At the same time, we need to recognize that different societal domains are governed by different information policies (Nissenbaum 2010). For example, with regards to unmanned aerial vehicles (UAVs), the acceptability of surveillance capabilities differs between military and civilian use, which should be reflected in the design of drones (Van Wynsberghe and Nagenborg 2016).

Context is also important for understanding whether and how robots of a certain type can be used to address morally relevant societal challenges. For example, the argument might be made that care-giving robots should be designed to assist rather than replace human care-givers (van Wynsberghe 2013). Here, providing care is seen as a morally relevant societal challenge in ageing societies. At 
the same time, a deeper understanding of the specific context of professional care is required to choose between alternative types and designs of robots.

The first requirement of RRI (developing robots that are helpful in addressing moral relevant challenges) asks us not only to give preference to morally relevant challenges but also to take seriously the moral character of the specific challenges. If we consider providing security to be a moral obligation and the use of drones to be a valid option in assisting police forces, we also need to consider the particular moral standards within the domain of policing to evaluate the design and use of drones in this particular context. For example, while stealth capabilities might be acceptable in the context of military usage, one may argue in favour of increasing the visibility of drones used for crowd-monitoring (Van Wynsberghe and Nagenborg 2016). Hence, for developing a substantive understanding of Responsible Urban Robotics we need to take into account the specific obligations for designing urban spaces.

\section{Responsible urban robotics}

"Responsible Urban Robotics" refers to the responsible design and use of urban robots. At a minimum, this includes consideration of the idea of value sensitive design and leads to the obligation to design robots to be safe, non-exclusive, privacy-sensitive, environmentally friendly, etc. This is what we should expect from all responsible robotics and every kind of responsible technological innovation. The same is true for the requirement to include multiple stakeholders in a participatory design approach. Again, this general requirement stems from the idea of Responsible Research and Innovation. To arrive at a more substantive concept of "Responsible Urban Robotics," we need to understand what sets this type of robots apart from others. Therefore, understanding robots as urban technologies is important. We need to recognize or anticipate the interplay between these robots and the city.

Although I am unaware of any specific report on RRI in the context of urban robotics, developing guidelines and provisions for this particular field will benefit from the examination of approaches from related fields. For example, reports on smart transportation systems can benefit from work undertaken on the political and ethical implications of transportation systems in general. In the domains of both smart and traditional transportation systems, we need to recognize that "today's planners and engineers ... must build around existing transportation infrastructures to produce good outcomes ... For the planner and the engineer, the 'different trolley problem' is building or incorporating alternative means such as streetcars or light rail systems into existing transportation systems to produce moral outcomes."
(Epting 2016) Thus, self-driving vehicles of different kinds need to be viewed as potential alternatives to already existing and envisioned transportation systems. Following Epting (2016), one could, for example, ask how self-driving busses could replace or compliment traditional busses and whether they might be helpful in overcoming the bias towards light rail systems and other less just alternatives (including the use of automobiles for individual transport). Additionally, designing urban transportation systems gives rise to justice issues. Those who do not have access to current transportation systems are exposed to harmful consequences either by the general negative impact on the environment or by being exposed to specific risk.

"For instance, suburban commuters outside Atlanta benefit from the highway system, but inner-city minority residents must endure the adverse effects from pollution. Poor residents living near highways in the Bronx visit hospitals for asthma-related illness more than any other group. ... What is more, minority groups that depend on inadequate transit systems lack access to several jobs, cannot access social services, or cannot partake in recreational activities due to scheduling restraints and time conflicts." (Epting 2016) A first step towards Responsible Urban Robotics and the use of robots as Responsible Urban Innovation is to acknowledge what is already known about the interplay between technologies and the cities, especially since such robotic systems will be integrated into pre-existing urban landscapes.

We may also gain insight from the discussion of so-called "smart cities." With regard to bringing the idea of value sensitive design in this particular context, Harbers et al. (2010) have argued that "citizens should be involved in the elicitation of current practices, concerns and wishes, in the evaluation of prototypes, and possibly even in the co-design of new solutions." They also highlighted the increased "chance of value tensions to occur" given the diversity of city inhabitants "with different cultural backgrounds, socio-economic statuses, preferences, priorities and values. ... The challenge is to design solutions that are still meaningful for all its users, despite their diverse values." (Harbers et al. 2010).

One may ask if values sensitive design is not bound to fail due to the diversity of the stakeholders involved and the size of the techno-social system. This is a valid question. However, first, we do have models for applying value sensitive design in architecture (van den Hoven 2013b) and larger techno-social systems such as offshore wind energy systems (Künneke et al. 2015). Second, the question of how to do justice to the diversity of city dwellers is addressed in the discussion on urban justice. We will return to this point later.

Another lesson to be learned is that "the fundamental question of "what kind of cities do we want to create and live in?' is largely reduced to technical issues within smart city discourse (e.g., a city where the traffic flows more efficiently, 
energy consumption is reduced, the crime rate is lowered, etc.) as opposed to considering this at a more profound level with respect to issues such as fairness, equity, justice, citizenship, democracy, governance and political economy." (Kitchin 2016) Neglecting this fundamental question might be partly due to the tendency to focus on specific aspects of city life. To stay with Kitchin's examples, a focus on traffic flows, energy consumption, or crime rates can be seen as positive. The current focus on smaller projects and initiatives marks a break from the market-driven, technologyfocused, one-size-fits-all approach favoured by industry and incorporates "participation, citizen engagement, bottom-up perspectives, and generally a complex and broad understanding of city life and urban planning into the drive for smartness." (Galdon-Clavell 2013) However, the more focused and sectoral approach may contribute to ignorance regarding the city as a whole. In this light, within the field of urban robotics, it may become important not only to design and implement robots for a specific aspect of city life but also to ask how innovation within one particular domain may impact development in other domains. For example, changes in the transportation system may impact the accessibility of education, work, or health care. Additionally, we also need to ask how innovations within one domain may or may not contribute to the kind of city we would prefer to live in.

\section{Designing robots for cityness}

One way to ensure attention to that more fundamental question is to ask how robots (or urban technologies in general) may promote the desirable qualities of city life. In this paper, the term "cityness" will be used as an umbrella term to refer to these desirable qualities.

Asking how robots may be designed for cityness may seem like an indirect approach towards addressing the fundamental question raised by Kitchin (2016), but the question provides us with a clear link between the specific design and use of robots and the broader discussion of what makes a good city. Furthermore, it indicates the possibility of making use of a discussion on a particular technology as an entry point for the general debate.

The term "cityness" has been introduced by Sassen (2010) to capture "types of urbanity that are 'non-western' or that in the West are novel and depart from traditional notions." The latter is relevant for our subject, since robots may indeed enable an urban future outside the traditional norms. Sassen herself has proposed thinking of cityness as the productive intersection of different lifeworlds. In her paper, she points to a street vendor in Midtown Manhattan who is creating a meeting point for tourists, secretaries, and businesspeople alike. Thus, selling food promotes cityness despite the fact that a built environment "sends out signals of neutrality, precision, engineering." (Sassen 2010 , p. 15) We may imagine a robot creating intersections in a similar fashion not only by serving a few-or only its "master"- -but also by stimulating interaction with and between many people. Unlike current devices that allow the creation of privacy bubbles and act as shields against the public, the presence of robots in public spaces might be seen as an invitation for engagement.

With regard to self-driving vehicles, considering cityness may encourage us to move beyond the idea of individual vehicles and design an alternative mode of (semi-)public transportation through which people may meet-or at least experience the presence of others. Robots may become instrumental in realizing some of the city virtues suggested by Young (1990) in her work on the city as normative ideal. These virtues need to be rooted in the experience of the city, including the erotic: "City life ... instantiates difference as the erotic, in the wide sense of an attraction to the other, the pleasure and excitement of being drawn out of one's secure routine to encounter the novel, strange, and surprising" (Young 1990, p. 239) In the foreseeable future, the presence of robots might be sufficient to contribute to experiencing the novel and strange. However, the implications of fostering the erotic aspect of city life might be more subtle and deeper. Where might the robots take us? Will a robot be a permanent feature of a specific place-a point of attraction becoming part of a pre-set routine of appreciation? Or will a robot guide - perhaps even persuade and seduce-us to playfully engage with the city and our fellow city dwellers?

In thinking about the design and use of urban robots, we may also consider another city virtue, the ideal of social differentiation without exclusion: "In the ideal of city life, freedom leads to group differentiation, to the formation of affinity groups, but this social and spatial differentiation of groups is without exclusion.” (Young 1990, p. 238) Urban social robots may contribute towards this ideal by being open to and respectful of various user groups. However, urban robots also pose a threat to this ideal. Vertical and horizontal smart transportation systems may become yet another example of "code/ space" (Kitchin and Dodge 2011). It is easy to imagine a vertical city in which smart transportation becomes a way to ensure that a user will meet only 'their own kind of people' and amplify the process of social sorting (Lyon 2007, Chap. 5). We should not be blind to this all- too-obvious threat.

\section{Urban justice}

As Weinstock (2011) has rightfully noted, the city has received relatively little attention in Political Philosophy, and discussions on justice still focus almost exclusively on the level of individual states and relationships between states. However, “...residents of cities affect one another to a greater 
degree than is the case for fellow citizens of a nation state that do not share space in the way that city-dwellers do." (Weinstock 2011) The idea of stakeholder involvement in RRI and value-sensitive design provides a good link to the discussion of urban justice. One could, for example, argue that we need to ensure that various groups of inhabitants and others (commuters, visitors of various kind, etc.) must be involved if they are affected by the introduction of a new technology into a city.

A typical challenge in the realm of urban justice is the spatial distribution of risks, as mentioned in the discussion on transportation systems by Epting (2016). We may also ask how new forms of transportation or new forms of human-robot interaction may play a role in working towards a just society. The use of UAVs for mapping of unplanned settlements to improve the living conditions of the inhabitants (e.g., Gevaert et al. 2015) may serve as an example here. Hence, urban robots are a potential threat to urban justice but also instrumental in overcoming injustice.

Finally, Young's work suggests a link between urban justice and cityness: "Because city life is a being together of strangers, diverse and overlapping neighbours, social justice cannot issue from the institution of an Enlightenment universal public. In contrast, social justice in the city requires the realization of a politics of difference." (Young 1990, p. 240) The city virtues of variety, eroticism, publicity, and social differentiation without exclusion need to be understood as parts of these politics of difference. Therefore, promoting cityness contributes to urban justice, since justice (and political deliberation and articulation in general) require publicity. At the same time, preventing exclusion contributes to minimizing injustice. It's worth noting that like "Responsible Research and Innovation," Young's account of "city life as a normative ideal" (Young 1990) cannot be reduced to a procedural account of justice. Young does, indeed, emphasize the need to create opportunities for interaction: "As a normative ideal city life provides public places and forums where anyone can speak and anyone can listen." (Young 1990) However, the deliberations in the public spaces should be informed by a democratic ideal, which she refers to as the "politics of difference."

One may still argue that a more substantial account of (distributive) justice is needed. However, in the context of this paper, it first must be recognized that the design and use of urban robots has to be considered within a larger discussion of urban or spatial injustice.

\footnotetext{
${ }^{4}$ In the context of urban planning, Fainstein (2010) has pointed out that participatory approaches have been developed since the 1970-ties in response to an overall technocratic top-down approach of urban governance. Although I do share her concern that participation has become the new standard tool, which may not be always adequate, her proposal to develop and focus on a theory of just urban planning goes too far and overlooks the benefits that stem from participatory practices (such as informing urban dwellers about planned and ongoing projects, community building, creating a sense of ownership, etc.).
}

\section{Robots as responsible urban innovation}

Thus far, we have discussed the specific requirements for the responsible design and use of robots in the context of the city. The focus has been on the design and use of urban robots. An alternative approach is to take cities and their needs as the starting point.

For example, the "Strategic Research and Innovation Agenda of JPI Urban Europe" 5 asks for a "mission- and demand-oriented, long-term programme addressing city and societal needs," "interdisciplinary approaches to enhance understanding of urban complexity," and "transdisciplinarity to ensure impact and relevance." (JPI Urban Europe 2015, p. 17) One of the key elements in the research projects funded by the JPI are so-called "Urban Living Labs," which strive for knowledge co-production and stakeholder involvement, especially in the context of experimental research in an urban environment. They also might provide viable opportunities for the development and use of urban robotics. In the context of sustainable development, Urban Living Labs "constitute a form of experimental governance, whereby urban stakeholders develop and test new technologies and ways of living to address the challenges of climate change and urban sustainability." (Voytenko et al. 2016) Although existing Urban Living Labs are diverse, the key idea is to develop and test new technologies in close collaboration with various stakeholders in an urban setting. Thus, Urban Living Labs can be viewed as both a forum and an approach (Voytenko et al. 2016). Given the potential impact on city life, it seems reasonable to ask for the use of this approach for developing and testing urban robots. ${ }^{6,7}$

\footnotetext{
5 "JPI Urban Europe" is one of the so-called "Joint Programming Initiatives," which were established by the European Commission in 2008 to implement the European Research Area (ERA). "JPI Urban Europe" was established in 2010 and currently has 13 member states. (http://jpi-urbaneurope.eu).

${ }^{6}$ In the private sector, Alphabet's Sidewalk Labs (https://www.sidew alklabs.com/) is an initiative designed to bring together technologists, urban research, and cities. Although one should remain sceptical about the long-term goal of establishing one integrated platform, we may nevertheless acknowledge that there are places in the cooperated world that seem to be willing to listen to the needs of cities.

7 (Urban) Living Labs are not without their critics. For example, Evans and Karvonen (2011) have voiced the concern that living labs, which often involve partners from the private sector, open the door “... for private interests to gain market share in the guise of helping society at large. Living laboratories aid and abet this appropriation by transforming the real world into a de facto research and development facility for capitalist modes of ecological modernisation." (Evans and Karvonen 2011) Although a detailed discussion on the criteria for the use and design of Living Laps lies outside the scope of this paper, it is safe to say that the idea of Living Labs requires considerable thought when being applied.
} 
Another entry point into exploring the responsible design and use of urban robots is the discussion on Public-Interest Architecture (Fisher 2008) or "Architecture for the other 90\%." (Lepik 2010) In addition to the use of robots in architecture and urban design, there are at least two links to urban robotics that must be recognized here. (1) Robots are spatial objects. They need to be somewhere. Therefore, they may require us to adopt the urban environment to their (functional) needs in a way similar to the required rearrangement of public space for the car and other forms of modern transportation. However, finding a suitable arrangement of material elements in space is the traditional domain of the disciplines of architecture, urban design, and urban planning. (2) As with architecture, robotics has the professional orientation towards serving the lucky few who are able to afford the services offered.

We must find a good spatial solution for integrating robots into the urban fabric, which first indicates that we need to recognize robots as spatial entities. Aside from taking (away) space by their mere presence, robots may also enable spacetaking practices since human-robot interaction occurs somewhere. Hence, as the practice of using mobile communication (especially smart phones) changed the practice of using public space, we must be aware of the potential changes introduced by more frequent human-robot interactions. Furthermore, we need to recognize the likely dependence of robots on the urban information ecosystem. For example, urban robots may need access to information about the area in which they are operating. For the built environment, this may lead to the question of whether geo-information systems and other forms of information infrastructure should be built for human beings, machines, or both? Will the city of the future be machine or human readable?

Finally, not all robots or robotic systems are or will be visible. They may very well find their place in the backstage of city life. Maintenance robots, such as the sewer inspecting robots mentioned above, are a prime example of this. Others, such as advanced vertical transportation systems, might be visible in principle but will still be perceived as being in the background of everyday activities. The way that urban robots will or will not become visible not only depends on their particular design but also on the design of the built environment. Although one may assume that humanoid social robots will be visible in public spaces just as humans are, the history of architecture recalls the hidden spaces of nineteenth century mansions in which the servants and maids were hidden from the eyes of the other inhabitants. In other words, recognizing (urban) robots as spatial entities requires us to think through the interplay between architecture and the built environment at large. Not only will robots need to find a place, but the design of the environment will also shape our interactions with them.
However, the dialogue between robotics, architecture, and urban design should not be limited to finding a suitable solution for the few who can afford both the services of robots and architects. The starting point for the movements advocating for social engagement in architecture has been summed up by Lepik (2010) as follows:

"Architecture can be a powerful instrument to affect social change. ... However, successful architecture-that which transcends the barest requirements to create a place of usefulness and beauty - is far from reaching all segments of global society, including large parts of the population that do not even have housing that meet basic needs. ... Faced with such challenges, ... questions inevitably arise regarding the role of the architect at the beginning of the twenty-first century: is it enough to simply be a service provider who works solely to fulfil commissions for clients who can afford such services? What proportion of the world's population is good architecture reaching today? How can architects use their training for the greater good?" (Lepik 2010, p. 12).

Along similar lines, we may ask how robots could be designed and used to serve the public interests rather than to meet the needs and desires of those who can afford the services provided. The previously mentioned use of UAVs for mapping slum areas might be seen as a first step in this direction since so-called "slum-upgrading" is one of the focus areas into which architecture might be extended (Bell and Wakeford 2008; Lepik 2010, pp. 12-22). Here, urban innovation may take the form of new designs, as in the work of the group ELEMENTAL (Aravena and Iacobelli 2016). Hence, we may ask, for example, how new forms and modes of construction may serve to address the needs of poor communities. We may also consider how new forms of smart transportation systems could provide people better access to education, the labour market, or food. This is not to claim that smart transportation systems or other forms of urban robotics should be considered as the prime solution to societal challenges. However, asking how urban robots may be helpful in serving the needs of the less well-off could be beneficial in reorienting the discussion about the design and use of (urban) robots in general.

\section{Summary of the findings}

In this paper, I have argued that we first must acknowledge that an interplay does in fact occur between robots and the city if we are to have a better understanding of that interplay. To highlight this co-shaping, I suggested studying robots as urban technologies similar to other technologies such as the car, the smart phone, or the elevator.

I have further distinguished between two approaches, Responsible Urban Robotics and robots as parts of 
Responsible Urban Innovations. In the first step, Responsible Urban Robotics was considered from the perspective of Responsible Research and Innovation. This led to the conclusion that urban robots should conform to basic RRI principles. We should expect a participatory design process to both ensure the societal desirability of the innovation process and its adherence to the idea of value sensitive design. In the second step, the need to consider that the specific design requirements for cities are addressed. I have suggested considering the findings from related fields, such as general works on transportation justice in the development of smart transportation systems, or the rich literature on so-called "smart cities."

One important insight from the smart city literature is the neglect of the fundamental question of which city we want to live in. To address this potential blind-spot, it has been suggested that we ask how we can design for cityness, which refers to the desirable qualities of city life. Here, I have suggested considering Young's city virtues as one potential starting point, especially since her work can also serve as an entry point into the discussion on urban justice.

By linking the idea of Responsible Urban Robotics with the discussion on urban justice, we arrived at the more demanding concept of "Responsible Urban Innovation." In contrast to "Responsible Urban Robotics," the second approach takes as a starting point both the needs of cities and the way that robots might be useful in addressing urban challenges. I suggested that this approach may require us to make use of "Urban Living Labs" to identify the relevant challenges and to explore how urban robots could be used to address these challenges. We may also find inspiration in the work undertaken on expanding the concept and field of architecture to ensure that architects not only provide services to the lucky few but also create useful and beautiful spaces for the many. A dialogue with architects, urban designers, and urban planners may also be needed to successfully address the spatial issues raised by the presence of robots in the city.

\section{Concluding remarks}

As stated in the Introduction, "Responsible Urban Robotics" and "Robots as part of Responsible Urban Innovations" are not mutually exclusive approaches. Ideally, every responsible design and usage of urban robots should be part of a responsible urban innovation. Still, the discussion should not be reduced to the latter approach as robots may simply enter urban spaces without being thought of as urban innovation. This will typically be the case with robots and robotic systems which are also used in urban spaces. Examples are social robots, mostly used in private spaces or professional settings, which also make use of public spaces. However, one may also think of smart transportation systems, which are also used in cities. In addition, it seems advisable to treat the two approaches distinctively, since designing for cityness also aims to benefit the city as a whole, whereas Urban Innovations may occur in a specific domain or part of a given city.

Although I could only outline the two approaches and the basic requirement of RRI in robotics in this explorative paper, we may nevertheless consider the following ranking of the three approaches:

(1) Responsible Robotics: The design and usage of all urban robots should confirm to the general requirements of responsible robotics.

(2) Responsible Urban Robotics: Urban robots should aim to promote and protect the desirable qualities of city life ("cityness").

(3) Responsible Urban Innovation: Urban robots should aim to identify and address the specific challenges of cities as part of responsible urban innovations.

This ranking suggests that we should consider urban robots to be problematic if they do not comply with the basic requirements. If a robot or robotic system is frequently used in urban spaces or directly impacts the built environment, the "Responsible Urban Robotics" approach should be applied. If robots or robotic systems are considered as "Urban Innovation," by contrast, we should still ask for protecting and fostering cityness.

Although I have proposed making use of the city virtues suggested by Young (1990) to develop a sound understanding of cityness, more work is obviously needed to further develop the concept. One advantage of using Young (1990) as a starting point is that she provides us with a link between cityness and urban justice. However, how cityness and urban justice relate to each other needs to be demonstrated in more detail. There might also be alternative accounts of both cityness and urban justice that need to be explored and developed. However, the findings presented in this paper suggest that both cityness and justice are two important values at stake.

Linking the discussion on urban robotics to the broader debate on Responsible Urban Innovations has the advantage of contributing to existing knowledge in other domains. It might also be helpful to address the question of professional identity, which is an important part of the discussion on expanding architecture. This route also comes at a price, as it may require robotics technologies to adapt to the research methodologies developed in this field and engage with the idea of "design as activism" (to quote the subtitle of Bell and Wakeford 2008) and forms of participatory action research (e.g., Freire 1982), which might not be suitable for the specific domain of robotics. 
Finally, it should be acknowledged that the concept of "urban robotics" might be misleading insofar as it gives preference to robots that are designed for use in cities or have a direct impact on the built environment. This may create a blind spot for the use of robots in production. The ongoing process of automation in industry and agriculture may actually have a greater impact on city life than the use of social robots in public spaces, smart transportation systems, and maintenance robots combined. We must be aware of this bias. In addition, we should also not ignore the fact that robots may simply not be the answer to the needs of cities and their dwellers.

Open Access This article is distributed under the terms of the Creative Commons Attribution 4.0 International License (http://creativeco mmons.org/licenses/by/4.0/), which permits unrestricted use, distribution, and reproduction in any medium, provided you give appropriate credit to the original author(s) and the source, provide a link to the Creative Commons license, and indicate if changes were made.

\section{References}

Ajuntament de Barcelona. (2014). Public end-user driven technological innovation (PDTI). Utility infrastructures ad condition monitoring for sewer networks. Robots for the inspection and the clearance of the sewer networks in the cities. Retrieved from http://echord.eu/ public/wp-content/uploads/2015/11/20141218_Challenge-Brief Urban_Robotics.pdf.

Anderberg, P. (2005). Making both ends meet. Disability Studies Quarterly. https://doi.org/10.18061/dsq.v25i3.585.

Aravena, A., \& Iacobelli, A. (2016). Elemental: Incremental housing and participatory design manual. Ostfildern: Hatje Cantz Verlag.

Association for Robots in Architecture. About RoblArch. http://www. robotsinarchitecture.org/about-robarch. Accessed 11 December 2016.

Bell, B., \& Wakeford, K., (Eds.). (2008). Expanding architecture: design as activism. New York: Metropolis Books.

Benedictus, L. (2014). Chinese city opens 'phone lane' for texting pedestrians. The Guardian. https://www.theguardian.com/world/ shortcuts/2014/sep/15/china-mobile-phone-lane-distracted-walki ng-pedestrians. Accessed 20 November 2016.

Blumenberg, H. (2009). Geistesgeschichte der Technik. Frankfurt am Main: Suhrkamp.

Buiter, H. (2008). Constructing Dutch streets: a melting pot of European technologies. In M. Hård \& T. J. Misa (Eds.), Urban machinery: Inside modern European cities (pp. 141-162). Cambridge, MA: The MIT Press.

Easterling, K. (2014). Extrastatecraft: The power of infrastructure space. London: Verso.

Epting, S. (2016). A different trolley problem: The limits of environmental justice and the promise of complex moral assessments for transportation infrastructure. Science and Engineering Ethics, 22(6), 1781-1795. https://doi.org/10.1007/s1194 8-015-9732-3.

JPI Urban Europe (2015). Transition towards sustainable and liveable urban futures: The Strategic Research and innovation agenda of JPI urban Europe. http://jpi-urbaneurope.eu/app/uploa ds/2016/09/JPI-UE-Strategic-Research-and-Innovation-Agend a-SRIA.pdf. Accessed 11 December 2016.

Evans, J., \& Karvonen, A. (2011). Living laboratories for sustainability: exploring the politics and epistemology of urban transition.
In H. Bulkeley, et al. (Ed.), Cities and low carbon transitions (pp. 126-141). London: Routledge.

Fainstein, S. (2010). The Just City. London: Cornell University Press.

Fisher, T. (2008). Public interest architecture: A needed and inevitable change. In B. Bell \& K. Wakeford (Eds.), Expanding architecture: Design as activism (pp. 14-18). New York: Metropolis Books.

Flanagan, M., Howe, D. C., \& Nissenbaum, H. (2008). Embodying values in technology: Theory and practice. In J. van den Hoven \& J. Weckert (Eds.), Information technology and moral philosophy (pp. 322-353). Cambridge: Cambridge University Press.

Franssen, M., Lokhorst, G. J., \& van de Poel, I. (2013). Philosophy of technology. In E. N. Zalta (Ed.), The Stanford encyclopedia of philosophy. Stanford: Stanford University Press.

Frearson, A. (2014). Revolutionary elevator uses magnets to move sideways. Dezeen. https://www.dezeen.com/2014/12/01/thyssenkru pp-multi-elevator-uses-magnets-to-move-vertically-and-horiz ontally. Accessed 7 December 2016.

Freire, P. (1982). Creating alternative research methods. Learning to do it by doing it. In B. Hall, A. Gillette \& R. Tandon (Eds.), Creating Knowledge: A research monopoly? Participatory research in development (pp. 29-37). New Delhi: Society for Participatory Research in Asia.

Friedman, B. (1996). Value-sensitive design. Interactions, 3(6), 16-23. https://doi.org/10.1145/242485.242493.

Galdon-Clavell, G. (2013). (Not so) smart cities?: The drivers, impact and risks of surveillance-enabled smart environments. Science and Public Policy, 40(6), 717-723. https://doi.org/10.1093/scipo $1 /$ sct070.

Gevaert, C. M., Sliuzas, R., Persello, C., \& Vosselman, G. (2015) Opportunities for UAV mapping to support unplanned settlement upgrading. Proceedings of GeoTechRwanda 2015. Rwanda Journal. https://doi.org/10.4314/rj.v1i2S.4D.

Graham, S. (2014). Super-tall and ultra-deep: The cultural politics of the elevator. Theory, Culture and Society, 31(7-8), 239-265. https ://doi.org/10.1177/0263276414554044.

Harbers, M., van Waart, P., \& Visser, E. (2010). Value sensitive design of smart cities, Paper presented at the Charting the Next Decade for Value Sensitive Design Workshop. Denmark: Aarhus.

Hård, M., \& Misa, T. J. (Eds.). (2008). Urban machinery: Inside modern European cities. Cambridge, MA: The MIT Press.

Kedmey, D. (2015). This ambitious startup plans to 3D print a bridge in Amsterdam. Time. http://time.com/3923167/3d-bridge-amste rdam. Accessed 11 December 2016.

Kitchin, R. (2016). Reframing, reimaging and remaking smart cities. Programmable City working Paper 20. https://osf.io/preprints/ socarxiv/cyjhg. Accessed 9 December 2016.

Kitchin, R., \& Dodge, M. (2011). Code/space: Software and everyday life. Cambridge: The MIT Press.

Künneke, R., Mehos, D. C., Hillerbrand, R., \& Hemmes, K. (2015). Understanding values embedded in offshore wind energy systems: Toward a purposeful institutional and technological design. Environmental Science and Policy, 53, 118-129. https://doi. org/10.1016/j.envsci.2015.06.013.

Lepik, A. (2010). Building on society. In A. Lepik (Ed.), Small Scale. Big Change. New architectures of social engagement (pp. 12-22). Basel: Birkhäuser.

Lin, P. (2016). Why ethics matters for autonomous cars. In M. Maurer, J. C. Gerdes, B. Lenz \& H. Winner (Eds.), Autonomous driving: Technical, legal and social aspects (pp. 69-85). Berlin: Springer.

Lundin, P. (2008). Mediators of modernity: Planning experts and the making of the 'car-friendly' city in Europe. In M. Hård \& T. J. Misa (Eds.), Urban machinery: Inside modern European cities (pp. 257-279). Cambridge, MA: MIT Press.

Lyon, D. (2007). Surveillance studies: An overview. UK: Polity Press. 
Mumford, L. (1963). The highway and the city. New York: Harcourt, Brace \& World.

Nissenbaum, H. (2010). Privacy in context: Technology, policy, and the integrity of social life. Stanford: Stanford Law Books.

Sassen, S. (2010). Cityness. Roaming thoughts about making and experiencing cityness. Ex aеquo, 22, 13-18.

Skinner, R., \& Bidwell, N. (2016). Making better places: Autonomous vehicles and future opportunities. http://www.wsp-pb.com/Globa ln/UK/WSPPB-Farrells-AV-whitepaper.pdf. Accessed 12 December 2016.

Smith, B. W. (2012). Managing autonomous transportation demand. Santa Clara Law Review, 52(4), 1401-1422.

Urban Robotics Lab. (2018). Welcome to urban robotics lab! http:// urobot.kaist.ac.kr. Accessed 11 December 2016.

van den Hoven, J. (2013a). Value sensitive design and responsible innovation. In R. Owen, J. Bessant \& M. Heintz (Eds.), Responsible innovation: Managing the responsible emergence of science and innovation in society (pp. 75-83). Chichester: Wiley.

van den Hoven, J. (2013b). Architecture and value-sensitive design. In C. Basta \& S. Moroni (Eds.), Ethics, design and planning of the built environment (pp. 135-141). Dordrecht: Springer.

van den Hoven, J., Jacob, K., Nielsen, L., Roure, F., Rudze, L., \& Stilgoe, J. (2013). Options for strengthening responsible research and innovation. Brussels: Directorate-General for Research and Innovation, European Commission.

van den Hoven, J., Lokhorst, G. J., \& van de Poel, I. (2012). Engineering and the problem of moral overload. Science and
Engineering Ethics, 18(1), 143-155. https://doi.org/10.1007/ s11948-011-9277-z.

van Wynsberghe, A. (2013). Designing robots for care: Care centered value-sensitive design. Science and Engineering Ethics, 19(2), 407-433. https://doi.org/10.1007/s11948-011-9343-6.

Van Wynsberghe, A., \& Nagenborg, M. (2016). Civilizing Drones by Design. In E. Di Nucci \& F. Santoni deSio (Eds.), Drones and responsibility: Legal, philosophical, and sociotechnical perspectives on remotelycontrolled weapons (pp. 148-165). London: Routledge.

Self Repairing Cities. (2018). Vision. http://selfrepairingcities.com/ about/vision. Accessed 5 July 2017.

von Schomberg, R. (2013). A vision of responsible research and innovation. In R. Owen, J. Bessant \& M. Heintz (Eds.), Responsible innovation: Managing the responsible emergence of science and innovation in society (pp. 51-74). UK: Wiley.

Voytenko, Y., McCormick, K., Evans, J., \& Schliwa, G. (2016). Urban living labs for sustainability and low carbon cities in Europe: Towards a research agenda. Journal of Cleaner Production, 123, 45-54. https://doi.org/10.1016/j.jclepro.2015.08.053.

Weinstock, D. (2011). Self-determination for (some) cities? In A. Grosseries \& Y. Vanderborght (Eds.), Arguing about justice. Essays for Philippe van Parijs (pp. 377-385). Louvain-La-Neuve: Presses Universitaires de louvain.

Young, I. M. (1990). Justice and the politics of difference. Princeton: Princeton University Press. 